\title{
O galego e a escola lingüística española
}

\author{
Manuel Rodrfguez Alonso
}

UNED

No mes de febreiro de 2002 analizabamos nun artigo aparecido na revista Tempos Novos, a forma aldraxante e carente de base científica en que era tratado o galego na xeneraljdade dos libros de texto de lingua española ou castelá que utilizan os escolares de todo o Estado español en ESO e Bacharelato, mesmo na propia Galicia. Como autores destes libros aparecían lingüistas españois tan acreditados coma o propio Fernando Lázaro Carreter, penúltimo director da Real Academia Española. Queremos profundar nesta liña sinalando cómo os prexuízos antigalegos, así como anticataláns ou antivascos, non veñen principalmente de políticos, xornalistas ou publicistas, que non teñen unha especial formación lingüística, senón dos lingüistas da chamada Escola española ou de Madrid ou de Menéndez Pidal. Xornalistas ou tertulianos, que desde medios coma $A B C$, El Mundo, a cadea COPE de Jiménez Losantos, etc., lanzan a súa furia castelanista e antigaleguista, ou anticatalana e antivasca, toman moitas veces os seus argumentos da vulgarización dos prexuízos de lingüistas profesionais pertencentes á chamada escola lingüística española ou de Madrid, fundada por Menéndez Pidal e verdadeira dominadora, case en exclusiva ata hai pouco, da filoloxía e linguística do Estado español. Por outra banda, estes profesionais da lingüística e da filoloxía descoñecen ou desprezan os estudios de lingüística que, especialmente desde os anos sesenta e sesenta, se veñen facendo en Galicia, Cataluña ou Euskadi. Como xa sinalamos no citado artigo de Tempos Novos, estes prexuízos pasan ós libros de texto que empregan os escolares de todo o Estado español, e así temos como resultado declaracións tan desafortunadas coma as que sobre as linguas non castelás de España apareceron nos labios de persoeiros da vida política e intelectual española na primavera de 2001 , coma a propia ministra de Educación e Cultura Pilar del Castillo, a propósito dun discurso do Rei, en que expresaba que as linguas non castelás nunca foron perseguidas en España. 


\section{A ESCOLA ESPAÑOLA OU DE MADRID DE FILOLOXÍA OU DE MENÉNDEZ PIDAL}

No remate do século XIX e comezos do XX Menéndez Pidal funda a chamada Escola Filolóxica Española ou de Madrid. Nas primeiras décadas dos anos trinta espállase coa Fundación do Centro de Estudios Históricos, vinculado tamén á daquela Universidade Central de Madrid. Esta escola ocupará antes e despois da guerra a práctica totalidade das cátedras de lingua e literatura das universidades, escolas normais de formación de profesorado de ensino primario e institutos de España. Como veremos, desde o seu propio fundador, caracterízase polo seu castelanismo a ultranza e antigaleguismo, anticatalanismo e antivasquismo. Estas ideas serán asumidas polo franquismo, especialmente polo Consello de Investigacións Científicas, liquidador do Seminario de Estudos Galegos e verdadeiro viveiro de lingüistas e catedráticos de filoloxía castelanistas. Baste cita-lo nome de Rafael de Balbín.

Esta escola española, fundada por Menéndez Pidal, ten como continuadores e/ou epígonos a Amado Alonso, Dámaso Alonso, Rafael Lapesa, Alvar, etc., ou os actuais Gregorio Salvador, Lodares, Quilis, Alarcos Llorach, ou o agora tan gabado Jon Juaristi, director do Instituto Cervantes, e segundo algúns medios «o mellor ensaísta española da actualidade», polo seu El bucle meláncolico, que no que se refire á cultura e lingua galegas, como tentaremos demostrar nun libro de próxima publicación non contén máis que parvadas e resulta dunha falta de documentación esmagante en alguén que é catedrático de filoloxía. Como xa indicamos, os membros desta escola española, dé Madrid ou de Menéndez Pidal ocupan durante décadas as cátedras de universidade, tribunais de oposicións, etc. e, así espallan o ideario desta escola, porque sabido é que, no endogámico mundo académico español e mesmo das editoriais e dos medios de comunicación, o que se move non sae na foto.

\section{O CASTELANISMO RACISTA DE MENÉNDEZ PIDAL}

Menéndez Pidal expón os seus argumentos a prol da língua, da literatura e da cultura castelás en moitos lugares e mesmo minimiza a importancia que Galicia tivo na Idade Media en tódolos terreos, desde a política á cultura. O que queira ter máis información sobre o castelanismo político de Menéndez Pidal e a marxinación de Galicia na consideración pidaliana e castelanista da Idade Media peninsular pode consulta-lo documentado libro A memoria de nación. $O$ reino de Gallaecia (Edicións Xerais), de Camilo Nogueira.

Posiblemente onde mellor aparecen resumidos e divulgados os prexuízos antigalegos, anticataláns e antivascos e furibundamente castelanistas de Menéndez Pidal sexa na conferencia de 1943, "Carácter originario de Castilla», 
pronunciada en Burgos, co gallo do milenario de Castela e aparecida como artigo en Castilla, la tradición, el idioma (Espasa-Calpe. Colección Austral). Menéndez Pidal, caracterizado con Unamuno ou Ortega na II República pola súa defensa acérrima do castelán e pola oposición ó galego, catalán e vasco e pola dura oposición neste tema a parlamentarios galeguistas como Otero Pedrayo ou Castelao, como ben estudiou José Antonio Durán en Crónicas I, considera que desde os tempos de Fernán González Castela leva mal o para el centralismo do reino leonés; non queren trasladarse os casteláns á corte leonesa para defender os seus preitos, pois iso vai contra o seu sentido de independencia -fixémonos que Castela si pode sentirse autónoma, independente; o resto das nacionalidades, non-. Os casteláns, segundo Pidal, non soportaban que os reis leoneses puxesen e quitasen condes na súa terra - os galegos, para Pidal, poden soportar iso e máis, polo superior talento administrativo dos casteláns, igual que ocorría co Imperio Romano. As virtudes da superioridade de Castela son o seu innato sentido democrático e igualitario que leva a facer fidalgo a todo aquel que poida manter un cabalo, a súa actitude de loita continua contra o Islam fronte ás ansias de vivir tranquilos dos occidentais leoneses e galegos polo que se converte Castela na salvadora de toda España, pois só ela $e ́$ intérprete do que verdadeiramente lle interesa ós españois: el papel preponderante de Castilla en conducir el imperio hispano hasta su cumbre, agotando en esa colosal obra todas sus fuerzas. Por outra banda, os casteláns destas datas son superiores porque fronte ó dereito escrito do vello reino de León, no que Pidal inclúe Galicia, herdeiro do dereito romano e escrito no Fuero Juzgo, impoñen un dereito espontáneo, baseado no criterio xusticeiro de persoeiros e non nos legalismos escritos, herdanza do vello dereito romano. Así os casteláns, di Pidal, un bo día segundo unha tradición muy respetable queiman tódolos exemplares escritos do Fuero Juzgo; fronte a el instauraron o dereito castelán baseado no sentido común e no sentimento espontáneo da xustiza que sentían estes casteláns primitivos de modo que estableceron, coma entre os antigo xermanos -reparemos na data, 1943, e xermanos, aínda vivo Hitler-, la responsabilidad penal colectiva, extendida a los parientes o a los conciudadanos del ofensor; la venganza privada; la prenda extrajudicial y otras formas de tomarse la justicia por la propia mano... Todo isto estaba ben porque o sentido xurídico espontáneo dos casteláns non necesitaba, segundo Pidal, desas vellas leis do Fuero Juzgo, propio dos atrasados e romanizados leoneses e galegos, tribunais, avogados, etc., continuadores dos decadentes romanos e non dos vitais xermanos, como era o caso dos casteláns. $O$ carácter innovador de Castela no dereito era pura pervivencia dos valores xermánicos en Castela. Isto hoxe pon colorado, polo seu ton racista e ata nazi. A Castela medieval é para Pidal un condado de homes que deixan pequeno a Harry o Sucio e a outros heroes antidemocráticos e filonazis no desprezo da lei escrita, no uso da forza e en facer xustiza 6 seu xeito, lonxe de calquera código escrito e pervivencia do dereito romano. Iso nin nas películas do Oeste, coma $O$ señor da forca.

Outra das singularidades de Castela, segundo Pidal, é a súa literatura, unha literatura épica, guerreira, enxalzadora da guerra e non a literatura que triunfaba 
na monarquía leonesa e asturiana, que non gustaban dos cantos épicos, de orixe xermánica. Aínda que non a cita, esta literatura sen forza, antipatrítica, teñen que se-los Cancioneiros, que apartan da furia guerreira e levan á molicie amorosa ou á crítica destructiva dos escarnios e maldicires, no pensamento de Pidal, ou que presentan cabaleiros que non queren acudir a guerra de Granada con Afonso X. Todas estas cousas, conclúe Pidal, hicieron necesaria la simbólica quema del Fuero Juzgo... Nesta literatura épica encómianse a vinganza privada, a extensión 6 s fillos das penas polos delictos cometidos por pais ou avós. Por outra banda, unha das grandes tradicións castelás encomiadas por Pidal é a vinganza do adulterio polo marido, que tamén salienta esta literatura épica castelá: lo privado repercute sobre lo público de tal modo que el hijo de Fernán González, en el poema épico, a causa de la infidelidad de su mujer, se cre (sic) incapacitado para seguir gobernando a Castilla, hasta obtener satisfacción por propia mano, y abandona su condado para perseguir, él solo, al raptor de la adúltera, matándolo sin ningún previo desafio, sino por sorpresa durante el suñeo, según las más fieras leyes del honor. Esta literatura épica, afortunadamente, segundo Pidal, arraigou en toda a Península desde Cataluña a Portugal.

Como vemos a Pidal non lle gustaba o espírito burlón dos Cancioneiros sobre a moral sexual: esa tolerancia é mala cousa e antipatrítica. Así mesmo non lle parecía nada ben o amor dos Cancioneiros; iso abrandaba e amolentaba os espíritos, que debían curtirse coa moral guerreira dos poemas épicos casteláns. Fronte Cancioneiros, o Poema de mío Cid. ¿Cantas veces no franquismo estudiamos, desde a escola primaria á Facultade de Filoloxía, o Poema do Cid, os da miña xeración? ¿E cantas nos falaron dos Cancioneiros? ¿Que pasa hoxe nas escolas, institutos e facultades de filoloxía do Estado español? Eu coido que, por desgracia, aínda lle gaña, e por goleada, o Poema de mío Cid ós Cancioneiros. O positivo, neste artigo-conferencia de Pidal, non é a tolerancia, o amor, o riso burleiro dos Cancioneiros, senón o código do honor calderoniano castelán. ¿Como pode soportar un espírito épico esas amigas que se laian porque o seu amigo ten que ir á guerra, para servi-lo rei, ou que se contenta porque o seu amigo xa non é almirante?

En canto ás linguas ocorre algo parecido. Os casteláns, segundo Pidal neste artigo-conferencia, bo resumo sobre a súa ideoloxía lingüística e mesmo política, desprezan por vellas e arcaicas as tradicións fonéticas latinas, que respectaban os outros falantes da Península, especialmente os occidentais: pronuncian ch donde la generalidad de los romances conservaba unha te del latín: mucho, derecho, dicho, etc., en de vez de muito, dereito, dito, o algo así que decian en Galicia y León... Tamén podiamos dicir que o galego é máis innovador e máis celta porque perde $0-l-$ e $0-n$-intervocálicos en lúa e cea e remontármonos á lenición celta, pero, evidentemente, non temos os galegos os prexuízos do señor Pidal. Fixémonos nese despectivo ou algo así, referido á pronuncia do $t$ de feito polos non casteláns, coma se os galegos ouveasemos no canto de falarmos claramente. Reparémos en que moi capciosamente Pidal $\mathrm{xa}$ está a introducir un dos tópicos que lle fixo moito dano 6 galego: o galego 
é xa desde o principio algo arcaico, vello, que no serve para os tempos novos; o castelán é o novo, o innovador, o que serve para adaptarse ós cambios e 6 progreso.

Fronte ós galegos e $\delta$ resto dos habitantes da Península naquela recuada Idade Media, que non estimaban a súa lingua, segundo Pidal, porque preferían o latín culto, os casteláns xa valoraban máis o seu romance có propio latín. Isto dío sen ningún apoio de cita nin dato histórico. Por outra banda, o castelán estaba fixado por esa nacente literatura épica e empregábase en documentos, contratos, etc. ¿É que os Cancioneiros non son literatura para Pidal ou os documentos galegos medievais son inventos dos pérfidos filólogos e escritores nacionalistas?

Esta sociedade castelá tan importante e cunha lingua tamén superior estenderase polos arcaicos e pusilánimes territorios hispanos para, coa súa lingua e leis, formar Nuevas Castillas. A razón desta vitalidade castelă fronte á decadencia do resto das comunidades hispánicas, especialmente a occidental, atópaa Pidal en que en Castela predominou o elemento germánico... muy poco influido por el romanismo... Así Castilla rechazó el Fuero Juzgo y floreció en costumbres germánicas y en poesía épica germánica. E aínda máis: ...la porción más evolutiva de un pueblo es la que por fuerza ha de dirigir los destinos de la comunidad...., la de más agudo espiritu de selección se adelanta a adoptar aquellas formas o maneras más convenientes a todos, más vitales y difundibles,..., según vimos ejemplificado en Castilla. Pero, ¿por qué é máis evolucionada a épica cós Cancioneiros? ¿Por que o Poema do Cid fixa o castelán e os Cancioneiros, prosa galega, prosa tabeliónica e documentos en galego non fan o mesmo? Iso non o di o Sr. Pidal. Así Castela pasa a constituírse en directora de una vida nueva entre los pueblos de la Península e cando faltaban recursos achega máis ca ningunha outra comarca, pois atendía ela soa á defensa y amparo de todo lo restante de la monarquía. Esa es la suprema prueba de la magnanimidad y sólo con magnanimidad pueden ser dirigidos los pueblos en convivencia pacffica duradera.

Que as demais rexións non entendan esta magnanamidade castelá que regala a súa lingua, as súas leis, como veremos máis adiante, para Pidal non é máis que envexa e resentimento.

\section{O TÓPICO PIDALIANO DA LITERATURA CASTELÁ MÁIS DESENVOLVIDA}

Obra de amplísima difusión foi o Manual de Gramática Histórica Española (1904) de Menéndez Pidal, manexado por centos de licenciados en filoloxía ata hoxe mesmo. No capítulo I desta obra Menéndez Pidal só fala de gallego-portugués. Despois engade que o castelán se estendeu polo 
ámbito galego e peninsular en xeral por servir de instrumento a una literatura más importante que la de las otras regiones de España. E engade que así recibe más propiamente el nombre de lengua española. Menéndez Pidal non proba esta afirmación tan categórica con ningún dato: ¿Seica os Cancioneiros non teñen valor literario ou son inferiores 6 Poema do Cid ou a Gonzalo de Berceo? Esta idea da superior literatura aparecerá recorrentemente ata os nosos días, como iremos vendo. Máis claro aínda resulta Pidal cando afirma en En torno al poema del Cid: o castelán esténdese pura e simplemente pola súa superioridade intrinseca: Recordad los tiempos en que Juan Lorenzo Segura escribía en leonés, Berceo en riojano, Alfonso el Sabio en castellano o en gallego, el Maestre Heredia en aragonés, el príncipe de Viana en navarro, Mosén Pere Torrellas en catalán o en castellano, y en esta lucha de tendencias va lentamente imponiéndose a todos el castellano, por la constante abundancia de su producción y por la frecuente superioridad de sus autores... La generalización del castellano es obra que secularmente se va consumando por la superioridad de sus juglares anónimos, por la de Alfonso X..., por la de la Celestina... Decatémonos de que Afonso $X$ é superior cando escribe en castelán a cando escribe en galego; pobre Meendiño e compañeiros seus dos Cancioneiros, pois calquera xograr castelán anónimo é moí superior a eles..., xa non digamos o autor ou autores do Poema do Cid.

Por outra banda (páx. 8 da citada Gramática histórica) Menéndez Pidal fala dun latín vulgar hispano-romano falado con particularidades dialectais en todo o actual Estado español, do que derivan, non o galego ou o catalán, senón tan s6 o español: Este idioma hispano-romano, continuado en su natural evolución, es el mismo que aparece constituído ya como lengua literaria en el Poema del Cid, el mismo que perfeccionó Alfonso el Sabio, y, sustancialmente, el mismo que escribió Cervantes. Loxicamente esta lingua española é froito do esfuerzo aunado de todos los espíritus cultivados y de todos los literatos insignes que se han transmitido el romance más general de España desde sus comienzos acá..., que por antonomasía se llama lengua española..., tanto que su nombre se aplica para designar el conjunto del idioma literario... É dicir, que desde a máis remota Idade Media xa o castelán, para Pidal español, era a lingua de todo o Estado. Pidal non coñecía nin os Cancioneiros nin a rica documentación medieval, nin o Rexurdimento...

Segue o delírio pidaliano cando afirma que pode usarse castellano cuando la unidad nacional no se habia consumado y cuando el leonés y el aragonés eran lenguas literarias. Pero desde fines del siglo XV la lengua que comprendió en sí los productos literarios de toda España no puede sino ser llamada española. Las otras lenguas que se hablan en España son ciertamente españolas también, pero non son el español por antonomasia. Castilla, la isla de Francia y Toscana son las cunas de los tres idiomas románicos principales. Fixémonos en que fala de que o leonés e o aragonés son linguas literarias, pero non o galego ou o catalán. Para Pidal, o galego e os Cancioneiros sinxelamente non existen. 


\section{O MITO DOS PRIMEIROS TEXTOS LITERARIOS}

Menéndez Pidal e toda a súa escola están obsesionados por amosar que os primeiros textos literarios que se nos conservan están escritos en castelán ou proceden de territorios do centro ou sur peninsular, aínda que estean en romance. Méndez Ferrín fala fermosamente no seu discurso de ingreso na Real Academia Galega dos esforzos ímprobos, argumentos falsos..., que emprega Pidal para data-lo Poema do Cid en 1140, pois non soporta que poida ser do século XIII, xa que o precedería no tempo a cantiga galego-portuguesa Ora faz ost'o señor de Navarra de Joan Soarez de Paiva, datada en 1197. Teima certamente infantil. Cando diferentes estudios, especialmente de filólogos ingleses, dan un feixe de probas para data-lo Poema do Cid no século XIII, os discípulos de Pidal revólvense, non aceptan a evidencia e aí están os argumentos esgrimidos na década dos oitenta do pasado século para defende-lo mestre e seguir datando o poema en 1140, que mesmo son recollidos polos filólogos máis novos, como Girón Alconchel na súa edición escolar do Poema do Cid na editorial Castalia Didáctica, unha das máis difundidas entre os escolares do Estado español. Nesta liña van tamén as loas que Dámaso Alonso fai da kharxas como primitiva lírica sen ningunha discusión. Así xa os galegos non se poden gabar das súas cantigas: as kharxas son algo propio do centro e sur de España, en definitiva, da zona castelanofalante e central. Reparemos en que esta polémica sobre qué textos foron anteriores é infantil, pero todo vale para xustifica-la primacía do castelán.

\section{O CASTELÁN LINGUA ESPONTÁNEA E TAN PROPIA DE GALICIA, CATALUÑA E EUSKADI COMO AS LINGUAS AUTÓCTONAS DESTAS COMUNIDADES}

Vella teima pidaliana, seguida por tódolos seus discípulos, mesmo os actuais Gregorio Salvador, Lodares ou en Galicia Janeiro, é que o castelán debe chamarse español, porque esta lingua en Galicia, Cataluña e Euskadi é tan propia dos nacidos nestas comunidades coma o galego, catalán ou éuscaro, respectivamente. Esta idea é defendida tamén por ensaístas e escritors como Julián Marías, Savater, Javier Marías, Muñor Molina, etc. Na etapa da transición (1975-1981) foron moitos os artigos de Julián Marías en que defende que castelán-español e galego, catalán e éuscaro son igual de propios e característicos das comunidades bilingües. Mesmo nos anos sesenta Marías falou sobre a casa da linguas dos cataláns, que é unha casa con dous pisos: nunha o catalán e noutra o castelán; tanto é casa dos cataláns a lingua catalana, coma a castelá ou española, española para Marías. Loxicamente, o andar superior ocúpao o castelán-español, pois é a lingua de todos, a que permite a intercomunicación coas outras comunidades, a que se abre cara á América, a que ten que ser a lingua do Estado. 
Pidal sempre que pode no perde ocasión para indicar que o español era a lingua que adoptan espontaneamente os falantes de toda España porque, como di en La lengua de Cristobal Colón, o español é unha lingua moderna por excelencia -por iso a aprende Colón e non o portugués-. Sobre Portugal, neste mesmo estudio afirma que los portugueses tomaban como lengua de cultura el español.

\section{O MITO DAS LINGUAS IMPERIAIS SUPERIORES E O CASTELÁN COMO LINGUA SUPERIOR}

O capítulo I do Manual de Gramática Histórica Española de Pidal é unha defensa clara do imperialismo lingüístico e fala de linguas superiores e inferiores e mesmo de razas. Así o latín é unha lingua superior e ben fixeron os pobos de razas e linguas inferiores someténdose a el: ... gracias a su talento administrativo, romanizaban rapidamente las razas sometidas y las hacian ir olvidando su idioma nativo, que no podía menos de resultar pobre e insuficiente para las complejas necesidades de la nueva vida que la colonización traía consigo. Además, la imposición de una lengua tan difundida como el latín. aunque molestara cariños y vanidades patrióticas, resultaba cómoda y útil para el comercio y la cultura...

Está ben claro: superioridade intelectual da lingua imperial e maioritaria sobre a minoritaria e do pobos sometidos, a súa maior utilidade para o comercio, para a administración, etc. Estas ideas o propio Pidal vainas aplicar para explica-la expansión do castelán sobre as outras linguas da Península e van ser utilizadas na actualidade polos seus netos, como Gregorio Salvador, Jiménez Losantos ou Lodares.

Pidal en El lenguaje del siglo XVI, falando da gramática castelá de Nebrija, afirma que os descubrimentos de 1492, las conquistas recientes y las proyectadas afirmaban el valor del propio idioma. A superioridade do castelán era innegable e, segundo Pidal, Gil Vicente e outros escritores portugueses úsano porque la primacía del habla de Burgos y Toledo estaba ya resuelta, non en el terreno político, sino, lo que vale más en el social y literario. Neste mesmo artigo Pidal sinala que cando se produce cos Reis Catolicos a unión entre Castela e Aragón debe optarse polo aragonés ou o castelán, los aragoneses se adhirieron, perspicaz $e$ inteligentemente a las modalidades castellanas..." Fixémonos que o catalán non existe para o mestre da filoloxía española. Un pouco máis adiante, neste mesmo, texto lémbrase do catalán e despáchao dicindo que lo mismo [que os aragoneses] pensaban los catalanes. Pidal segue dicindo que o castelán era adaptado por todos porque era a lingua do bo gusto, da cortesía. Mesmo non se corta nada e aduce que é a lingua máis fermosa: la lengua escrita [castellanal produce la modalidad sin duda más hermosa que jamás se escribió en España... Por outra banda era a lingua apta para os 
proxectos imperiais de Carlos V: ... y se fragua la lengua de todos, buscando para ella la máxima eficacia en la edificación del pueblo español, pueblo de cruzados, defensor de la cristiandad y ejecutor del concilio de Trento. Xa que logo, lingua castelá -española para Pidal-, patriotismo, catolicismo e expansión imperial van unidas. Non é fume de pallas que Pidal considere que esta é a lingua dos conquistadores de América. No seu artigo sobre Las Casas

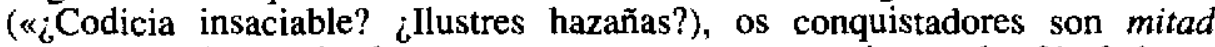
viquingos, mitad apóstoles, que non se moven nas conquistas polo afán de lucro nin poder senón polos altos ideais de engrandece-lo seu rei e patria, servir a Deus espallando o catolicismo e buscando a gloria, como facian os antigos centurións e xenerais do exército romano. Di, coma o mellor e máis conservador Maeztu, que el conquistador es la gran aportación de España al Renacimiento, mitad cruzado-mitad caballero andante. Estes conquistadores son os grandes civilizadores e gracia a eles os pobos conquistados alcanzan buena policía. justicia y religión. Estes conquistadores posúen ideas ambiciosas e nobres para a humanidade que s6 poden expresarse nunha lingua maioritaria, pois as linguas minoritarias non son quen de expresar nobres arelas: Ninguna idea ambiciosa $y$ noble se resigna al particularismo de una lengua local. Pidal engade no artigo La lengua española que as linguas minoritarias non serven para estes homes de acción e civilizadores desinteresados: Las variedades regionales viven en el vulgo, ligada al territorio donde nació... la lengua culta se dilata... y se difunde por la actividad de los hombres de acción... fuera del lugar donde él nació... para lograr el mayor alcance en el espacio y en el tiempo. Xa que logo imperialismo puro e duro. Os que se contentan en permanecer nos seus límites, sen invadir ós outros, os que se resignan a vivir nas súas fronteiras, as linguas que non se estenden a custa doutras dun xeito imperialista é porque nestas linguas non se pode expresar ou non hai nesas culturas ninguna idea ambiciosa y noble. Certamente Menéndez Pidal non subscribiría aquilo do himno de Pondal de que $O s$ bos e xenerosos / a nosa voz entenden... Ou tal vez a Pidal, e os seus seguidores actuais, habería que incluílos nos seguintes versos pondalianos: mas sos os ignorantes / e feridos e duros, / imbéciles e escuros. I non os entenden, non.

O discípulo de Pidal, Américo Castro, non dubida en afirmar: La historia se hará en adelante como un independiente caminar hacia el sur de seis grupos humanos -gallegos, leoneses, castellanos, vascos, aragoneses y catalanesque, como seis jinetes, inician su marcha pertrechada cada uno con su habla y con su plan de vida. Del entrecruce de sus vidas bajo la fuerte mano de Castilla saldría el modo existencial de los españoles...

A superioridade intrínseca castelá fai que teña que ser rectora do resto dos pobos de España. A lingua ten que impoñerse, pois é a única con falantes con esa vontade civilizadora, segundo Pidal e os seus, moderna, etc. Xa se sabe nas linguas pequenas non cabe ningunha idea nobre nin ambiciosa. Lembremos que Pidal escribe estes artigos entre 1919 e 1933, cando actuaban as Irmandades da fala que $x a$ non se conformoban con que $o$ galego fose só unha lingua poética, cando se elaboran plans para a autonomía 
galega, cando xorde o Seminario de Estudos Galegos, etc. Pidal vía que os sometidos, que os apoucados, que os asoballados xa non estaban dispostos a aceptar tan facilmente as imposicións civilizadoras e que non querían que ninguén os salvase.

\section{A OBSESIÓN POLO TERMO ESPAÑOL FRONTE A CASTELÁN}

Vimos un pouco máis enriba que Menéndiz Pidal xa fala na época da conquista romana dun primitivo latín español do que procede sen máis $o$ español. A escola linguiística española ten unha teima en que hai que denominalo castelán español, porque todo o Estado español sente esta lingua como propia e porque neste español conviven tódalas linguas e dialectos de España, pois na pronuncia, no léxico e na morfosintaxe vai tomando trazos de tódalas terras e homes non só de España, senón mesmo de América. A teima da denominación español comezouna dentro da Escola española o propio Menéndez Pidal. Por outra banda, o castelán é o español por excelencia e as outras linguas non o son. Actúan realmente como factores disgregadores da nación e do Estado españois. No citado artigo de 1919 «La lengua española» amósase feliz porque, por fin, a propia Real Academia Española decide en 1925 adoptar o termo español no canto de castelán no diccionario académico deste ano. Lembremos que esta data, 1919, coincide máis ou menos co xurdimento das Irmandades da Fala -1916-e mesmo con outros movementos rejvindicadores da lingua en Cataluña e Euskadi. Así mesmo alporízase contra un anónimo gramático de Lovaina que en 1559 publicou unha gramática en que dicía que tan españolas coma o castelán eran as outras variedades lingüísticas faladas na Península. Trátao de envexoso e resentido. Este pobre gramático vai recibir toda unha serie de labazadas morais por parte do pidaliano Amado Alonso, no libro síntese das concepcións da escola lingüista española sobre as linguas de España, Castellano, español, idioma nacional, que veremos un pouco máis adiante. Menéndez Pidal continúa e no seu ensaio La lengua en tiempos de los Reyes Católicos afirma: desde fines del siglo XV la lengua que comprendió en sí los productos literarios de toda España (pues en ella colaboraron hasta los más grandes autores portugueses, como Gil Vicente y Camoens) no puede sino ser llamada española. Las otras lenguas que se hablan en la Peninsula, son ciertamente españolas también, pero no son el español por antonomasia... Como se ve, implicitamente a única lingua culta, cunha literatura, segundo Pidal é a castelá. As outras son simplemente iso otras lenguas que se hablan en la Península. Este palabra as outras callou tanto nos pidalianos e na mesma Real Academia Española que a Ortografía de la lengua española de 1999 opón na súa páxina 133 o concepto de topónimos españoles cos topónimos correspondientes en alguna de las otras lenguas de España. Mesmo a RAE fala despectivamente destes topónimos das otras linguas de España, porque non di que son históricos, tradicionais, como fai cos topónimos casteláns, senón que di 
que que toma os toponimos non castelás da obra Entidades Locales en España, publicada por el Ministerio para las Administraciones Públicas, donde figura la relación oficial de tales entidades, con los nombres que estas han preferido registrar. É dicir, os topónimos casteláns están autorizados, segundo a citada Ortografía da RAE, con documentación que avala su empleo tradicional en castelano; os galegos, castelans e vascos son os que eljxiron os topónimos das súas entidades 6 chou ou por capricho diferencialista: coma se dixeramos, dámoslles a razón si para que calen coa teima de que os topónimos deben aparecer na lingua de orixe e non castelanizados.

Volvendo ás teses de Pidal, sinala que cando alguén quere escribir cousas de calidade, acode 6 castelán, español para Pidal, como fixeron mesmo os portugueses Gil Vicente e Camoéns, o gran clásico portugués. Por outra banda, o castelán non ten case diferencias co resto das linguas de España e compréndeas a todas: ...las diferencias entre las hablas catalanas, aragonesas, castellanas, etcétera son sin duda menoros en número y calidad que las que existen entre las ladinas, lombardas, piamonontesas, toscanas, etc., o entre las variedades picardas, francesas, provenzales, languedocianas y gasconas. De aquí a dicir que o galego ou o catalán non son máis que dialectos do castelán non hai máis ca un paso. E xogando moi capciosamente Pidal coa ambigüidade faino no citado artigo de 1919: En España los dialectos retroceden... Triunfa la lengua culta sobre las lenguas regionales... El castellano no es una importación...

Así mesmo, Pidal e os pidalianos afirman que o español foi admitindo elementos de tódalas linguas e dialectos de España, polo que xa non se pode chamar castelán, senón español, pois nel recoñécense elementos leoneses, aragoneses, etc. Digamos que Pidal sempre que pode, e os seus seguidores, evitan falar de galego, catalán..., e prefiren falar de falas occidentais, o oeste do reino de León... Lémbrannos a algúns burócratas centralistas actuais que falan da Autoestrada do Noroeste e non queren oír falar de Autoestrada de Galicia, nin sequera das Rías Baixas. Mesmo tampouco da Coruña, se acaso de La Coruña. Algún académico da Española escribiu no $\mathrm{ABC}$ madrileño recentemente que non se entendían os rótulos postos na saída de Madrid na A-6 porque din A Coruña e a xente non sabe se iso é A Coruña (La Coruña para eles) ou Cara á Coruña. Este académico, licenciado en filoloxía, ten menos sentido linguístico cós milleiros de persoas sen especial formación filoloxica que percorren estas estradas e non atopan ningún problema co topónimo A Coruña. En fin, os filólogos da escola española deparan estas sorpresas: hai anos o que este escribe tivo que escoitar de D. Carlos Alvar na universidade de Alcalá que os carteiros de fala non catalana de Cataluña podían non entende-los topónimos en catalán... . Os carteiros nunca protestaron, do cal podemos deducir que os carteiros tarnén teñen máis sentido linguíístico ca algún catedrático de filoloxía.

Volvendo 6 conto, esta afirmación pidaliana que repiten alegremente tódolos seus discípulos contradise despois coa realidade e a práctica. $O$ propio Menéndez Pidal no citado artigo La lengua española di que a pronuncia que se debe ensinar e esixir, mesmo en zonas seseantes de Andalucía ou 
Hispanoamérica, é la pronunciación de las regiones castellanas. No que se refire a morfosintaxe e 6 léxico tamén hai que preferir as formas castelás pois están más cerca del prototipo sintáctico y léxico tradicional, cuya continuidad conviene mantener. Loxicamente, se vostedes consultan o Manual de Pronunciación Española de Navarro Tomás, o máis recente de Quilis Morales, as gramáticas da RAG, as gramáticas normativo-descritivas máis usuais, etc., - que priva é a norma castelanista e académica. Eu non lembro ver ningún manual de pronunciación española que trate da pronuncia das vocais no castelán de Galicia e da posible influencia sobre o sistema vocálico castelán de cinco vocais no castelán de Galicia do vocalismo galego de sete; non vin citado o pronome de solidariedade en ningunha gramática castelá... Xa que logo norma de Castela pura e dura. E aínda máis, norma da Academia madrileña. Tanto é así que Pidal no artigo El diccionario ideal, de 1953, compara o diccionario da Real Academia Española co New English Dictionary de Oxford e ¿saben cómo denomina o diccionario da RAG? ¡Diccionario de Madrid! O lapso do veterano filólogo é ben expresivo. ¿Ou non é lapso?

Por outra banda o que isto escribe lembra da súa experiencia persoal cómo competentes lingüistas formados na escola española e catedráticas de latín de ensino medio nos anos sesenta se alporizaban porque os galegos non usabamos os tempos compostos e sobre todo nas traduccións no canto de había amado traduciamos amara. Aínda nos comezos dos anos setenta se podía escoitar cómo na universidade de Santiago a profesora de historia do español Carmen Bobes dicía que os alumnos de filoloxía de Santiago nas oposicións de cátedras de Ensino Medio, daquela de nivel estatal e celebradas en Madrid, podían ter serios problemas pola súa fonética galega de vocais abertas e pechadas, mala pronuncia dos grupos cultos, etc., co que os alevíns de filólogos e opositores quedabamos certamente abraiados e ata viamos como marca infamante o noso castelán inzado de certos galeguismos, que nós daquela estudiantes desinformados do final do franquismo non eramos quen de corrixir nin case descubrir.

\section{A SISTEMATIZACIÓN DE AMADO ALONSO EN CASTELLANO, ESPAÑOL, IDIOMA NACIONAL E A SÚA EXTRAORDINARIA FORTUNA}

Amado Alonso, membro caracterizado da escola española, recolleu estas ideas ciscadas alá e acolá polo seu mestre Pidal e formulounas ordenadamente nun libriño, edítado por primeira vez en 1943, e que é resumido por tódalas historias da lingua española que tratan o tema da extensión do castelán, desde a tópica e típica de Rafael Lapesa -Historia de la Lengua Española-, libro obrigado en tódalas facultades de filoloxía do Estado español, ata os productos máis recentes, derivados en gran medida de Lapesa, como El español a través de los tiempos, de Rafael Cano Aguilar. 
O libriño de Amado Alonso, Castellano, español, idioma nacional, publicado en 1943 tivo un éxito extraordinario no españolismo e segue a inspirar a toda a escola española. Como bo discípulo, Amado Alonso abre o libro repetindo as xa comentadas ideas de Pidal sobre a superioridade de Castela, do seu idioma, da súa cultura, das súas xentes. Mesmo parece que copia as ideas do mestre ó pé da letra, como pode observa-lo lector se compara as afirmacións que seguen coas que facía Pidal e que tratamos no capítulo anterior.

Amado Alonso inicia o seu libro cunha afirmación que asinaría o seu mestre Pidal, pois non só lle copia o espírito, senón mesmo a letra: Las gentes de aquella comarca [Castela] vivian lo heroico como normalidad de sus vidas $y$, haciendo de la necesidad virtud, desarrollaron unos rasgos peculiares de carácter y atrofiaron en sí otros que se cultivaban como flor de cultura en la corte de Oviedo. Aquellos hombres se hicieron eficaces y rectos, acostumbrados a las resoluciones prontas y perspicaces... Ni siquiera se fiaban de la legislación escrita que regía en el resto de España con el nombre de Forum Iudicium o Fuero Juzgo; ellos se habian de administrar justicia "por albedrío» según el derecho consuetudinario local. iCuánto menos iban a andarse atentos a seguir los modos ovetenses de hablar! Loxicamente onde se le Oviedo, ovetense hai que estendelo a todo o Occidente peninsular, incluído Galicia: é tanta a teima antinacionalista e antigaleguistas que Menéndez Pidal, Amado Alonso e os seus discípulos evitan sempre que poden Galicia, Santiago de Compostela, galego. Engade que por esta superioridade os casteláns teñen que exerce-la súa enerxía combativa no sólo contra los moros, sino también contra sus reyes forasteros... Para nada se fala da existencia do galego no reino medieval de Lé́n por parte de A. Alonso, senón do leonés: Los leoneses sabían que aquellos sus arriscados súbditos [os casteláns] hablaban la misma lengua que ellos, pero con cierta desgarrada rusticidad... y sin tantos miramientos conservadores y latinizantes... A los cristianos de otras tierras les resonaba como trompeta con tambor... Xa vemos que nada de dozuras, saudades nin amores, as linguas boas son as que resoan como tambor e trompeta militares.

Por outra banda, a falacia de Amado Alonso lévalle a dicir que na Idade Media peninsular convívían só dúas variedades lingüística: o latín e o romance: El latín, como lengua de la cultura escrita; el romance, como lengua de la acción en sociedad. Ninguén falaría, segundo Amado Alonso, de "romance leonés», «romance ovetense»... Para nada se citan galego, catalán.

\section{OS EXEMPLOS DOS GRAMÁTICOS}

Amado Alonso está obsesionado por demostrar que os gramáticos e lingüistas desde o século $\mathrm{XV}$, nas súas gramáticas, diccionarios e obras de estudio da lingua castelá, a denominan española. Os exemplos son patéticos e 
eles mesmos amosan a febleza dos argumentos. Amado Alonso no se decata, ou mellor agocha, que Nebrija titulou a súa obra Gramática de la lengua castellana e tamén usou castelán e non español para a súa Reglas de Ortographía en la Lengua castellana. Valdés no seu Diálogo de la lengua utiliza habitualmente lengua castellana. Ambrosio de Morales publica en 1546 Discurso de la lengua castellana. Martín de Viana publica en 1574 o Libro de alabanças d'las lenguas hebrea, griega, latina, catellana y valenciana. Alderete tamén usa castelán no seu Origen y principio de la lengua castellana o romance que oi se usa en España (1606). Mateo Alemán segue a mesma liña na súa Ortografía castellana (1609). Cristóbal de Villalón ofrece a Gramática castellana. Arte breve y compendiosa para saber hablar y escrevir en la lengua Castellana congrua y decentemente (1558); Baltasar de Sotomayor, a Gramática con reglas para aprender a leer e escribir la lengua Francesa conferida con la Castellana (1565); Gustavo Correas, Arte grande de la lengua castellana (1626); Gonzalo de Correas, a súa Trilingüe de tres artes de las tres lenguas Castellana, Latina y Griega (1634). No século XVIII a gramática máis influente, antes da académica, é a Gramática castellana de Benito Martínez Gayoso (1743). Mesmo a primeira gramática histórica, anterior en dous anos á de Pidal é Estudio elemental de gramática histórica de la lengua castellana, de José Alemany Bolufer (1902), hoxe esquecida, pero que introduciu os estudios de gramática histórica en España e popularizou a metodoloxía de Diez e Meyer-Lübke.

A propia RAE titula a süa gramática Gramática de la lengua castellana (1771). Só a partir dos anos 20 e 30 do século XX a Real Academia Española asume español: na edición do seu diccionario de 1925 cambia castelán por español. Mesmo os lingüistas españois e hispanoamericanos modemos, basicamente do XIX e ata do XX, xeralmente, aluden ás súas obras con castellano e non español: Cuervo, Bello, Salvá, o conde de la Viñaza, Eduardo Benot, Rosenblat, Henríquez Ureña... Só a partir do predominio da escola de Menéndez Pidal aparecen os nomes de español en gramáticas coma as de Rafael Seco, Manuel Seco, Fernández Ramírez, Alarcos Llorach, etc., todos eles ligados, dun xeito ou doutro, á escola de Madrid e sempre en obras publicadas a partir da década dos trinta do século XX. Curiosamente os filólogos non casteláns prefiren nos seus títulos castelán. Así, Badía Margarit, na súa Fisiognomía comparada de las lengua catalana y castellana ou Francisco de B. Moll en $E l$ castellano de Mallorca. A tradición gramatical galega tamén usa habitualmente castelán e non español. Así, os diccionarios son bilingues galego-castelán usan castelán ou castellano e non español: así desde o primeiro diccionario castelán-galego, o de Francisco Javier Rodríguez. (1863), chegando 6s actuais de Xerais, Ir Indo, Galaxia, Vox, etc. A mesma Real Academia Galega titula Diccionario gallego-castellano o seu primeiro diccionario -que só chega á palabra cativo- e publicado entre 1913-28 ou o máis moderno Diccionario Manual Castelán-Galego publicado pola Voz de Galicia 6 longo do ano 1997. Desde Pintos en A gaita galega, castelán contraponse a galego e na tradición gramatical galega predomina claramente 
o termo castelán e non español. Se se consulta o valioso estudio de Carme Hermida Os precursores da normalización (Vigo: Xerais, 1992) veremos que nos gramáticos e estudiosos preocupados pola situación do galego o normal é falar de castelán e non de español. A teima de Pidal, e agora de Amado Alonso, pouco despois de Alvar, Gregorio Salvador, Lodares, etc., por denominar español o castelán e porque se considera que o castelán é tan propio de Cataluña, Euskadi e Galicia coma o catalán, galego e vasco. Négase que os castelán se impuxese nestas comunidades por un presión política e legal que eles non recoñecen e non aceptan iso de que o galego é a lingua propia de Galicia. Din que tan propio coma o galego é o castelán; de aí que haxa que chamarlle español e que a lingua española por antonomasia, como quería Pidal, é o español. No fondo, como veremos máis adiante, de acordo cunha vella idea de dona Emilia Pardo Bazán, consideran que as linguas non castelás de España son sinónimo de separatismo, antiespañas, antivalores da España tradicional, como xa vimos en Pidal.

Deste xeito, as testemuñas que achega Amado Alonso, e que aceptan Lapesa e toda a escola linguística española, sobre o emprego de español no canto de castelán son realmente patéticas. Non consideran as gramáticas máis rechamantes e influentes desde a castellana de Nebrija (1492) ata propia da Academía do século XVIII. Fronte a isto cita Amado Alonso o rexistro que da súa biblioteca fixo Fernando Colón no século XVI en que emprega habitualmente o termo español ou de gramáticas que non acadaron o presitixio das que acabamos de citar.

\section{A EXTENSIÓN DO CASTELÁN NAS COMUNIDADES NON CASTELÁS}

Do mesmo xeito que facía Pidal, Amado Alonso adopta o nome de español porque quere dicir que esa lingua é tan propia de Galicia, Cataluña e Euskadi coma o galego, catalán e éuscaro. En canto á penetración do castelán en territorios non castelás segue 6 pé da letra as ideas pidalianas. Non houbo procesos centralizadores, non houbo cambio de nobres trala guerra civil Pedo I - Enrique II, non existiu a política centralizadora dos Reis Católicos nin a norma de Toledo de 1480 que obrigaba ós escribáns e notarios a examinarse en Valladolid e ser quen de utiliza-los formularios casteláns, non houbo Decreto de Nova Planta, non existe a Real Cédula de Carlos III impoñendo nas escolas a gramática castelá da Real Academia Española.... Nada diso existe. Segundo Amado Aloso un bo día o castelán nunha época remota chámabase así e por iso se distinguía do galego, do catlán... Pero espontáneamente o castelán saliendo de su casa castellanizó el centro y sur de la Peninsula, y luego se unificó con los reinos de León, Navarra y Aragón, que adoptaron en común el hablar de Castilla. Como se ve non houbo ningún tipo de presión, non existíu unha 
chancelería coma a de Fernando III ou Afonso X, ou as medidas legais aludidas antes para o espallamento do castelán: foi algo espontáneo, pois toda España adoptou o común falar de Castela. Non se diga que daquela estaba atrasada a filoloxía: ie que seica $D$. Amado non foi testemuña nos anos da República sobre a cooficialidade de catalán, galego e vasco que se desenvolveron no Parlamento e que tanta tínta lles fixeron gastar $6 s$ xomalistas? ¿Un lingüista tan preparado non lería a crónica que sobre a cooficialidade do galego escribiu Wenceslao Fernández Florez a propósito da intervención sobre o tema de Castelao no Parlamento e que foi respondida por Unamuno? Por outra banda, Amado Alonso non repara en que cando el escribe este ensaio, máis aínda cando Pidal, escribía os artigos citados no capítulo I a lingua falada maioritariamente en Galicia era o galego. ¿Eran estes filólogos de elite e altamente cualificados descoñecedores, por exemplo, das propostas normativizadoras das Irmandades, dos traballos do Seminario de Estudos Galegos, da propostas do Partido Galeguista ou mesmo da revista Nós, que foi saudada con admiración polo propio El Sol cando saíu en 1920 ? Ou calan a mantenta porque cómpre agochar a realidade do galego?

\section{UN NOVO CONCEPTO DE NACIONALIDADE: A NACIONALIDADE ESPAÑOLA OU CASTELÁ}

Esta adopción espontánea do castelán dáse porque en España xorde un novo concepto de nación, propagado desde Castela, que impón os obxectivos ó resto de España, de acordo coas novas ideas renacentistas e non coas atrasadas medievais que mantén o resto de España, segundo Amado Alonso. É a vella idea de Castela e os conquistadores casteláns como civilizadores que xa citara Pidal e que analizamos no capítulo anterior. Castela ten unha idea imperial, unida ó engrandecemento territorial, $\sigma$ espallamento das súas leis e dos seus costumes e á extensión do catolicismo como relixión universal. $\mathrm{O}$ bo patriota ha de ser imperialista, católico e ha de falar en castelán. O castelán para Pidal, Amado Alonso e os seus seguidores é o novo latín, pois agora repetíase a historia do latín e da alta misión civilizadora de Roma; só hai que cambiar Roma por Castela e latín por castelán: la historia imperial del latín renacida y reproducida en la inmanente historia del castellano.

Como non podía ser menos Amado Alonso adoba todo isto con citas históricas ou pseudohistóricas triunfalistas sobre o español atribuídas a Carlos $V$ ou a outros personaxes da época: Carlos V pronuncia en Roma ante el Papa. su corte y los embajadores extranjeros un discurso en su propia lengua; $y$ como el obispo de Mâcon, embajador francés, se quejara de no entender, el Emperador replica con orgullo apenas frenado por la cortesia: "Señor Obispo, entiéndame si quiere, y no espere de mi otras palabras que de mi lengua española, la cual es tan noble que merece ser sabida y entendida de toda la 
gente cristiana». La lengua castellana, magnificada al sobrarse de la región y al identificarse con el poderoso imperio.

A cita é longa pero non ten desperdicio. O castelán é a lingua do imperio para Amado Alonso, fronte os particularismos pailáns, pois o imperio centralizado é a cjvilización. O conquistador, ou funcionario diriamos nós, non ten por qué sabe-la lingua do conquistado, que é superior: se o inferior quere ser atendido, que aprenda a lingua superior do emisario ou funcionario do Imperio. Ben claro llo di Carlos V ó propio bispo de Mâçon e embaixador papal. Se isto llo din a un embaixador papal, que non lle dirian a un labrego ou artesán que non soubese castelán... Amado Alonso sente un infínito pracer ante esta resposta que lle dá Carlos $V$ ó embaixador e que nos fai lembrar a eses funcionares que din Hábleme en cristiano. Decatémonos que a cita di que a lingua castelá ou española ten que ser entendida por toda a gente cristiana. $\mathrm{O}$ que non a entende, implicitamente non é cristián ou é mal cristián, aínda que sexa o propio bispo e embaixador papal. Amado Alonso remata fachendoso dicindo que a lingua castelá supera a rexión ó identificarse con el poderoso imperio. Son as mesmas ideas que vimos en Pidal, que seguirán na Historia de la lengua española de Lapesa (incluso na edición de 1981 e posteriores, xa aprobada a Constitución de 1978 ou os Estatutos de Autonomía). Polo tanto a idea do castelán-español como lingua imperial, como latín dos tempos novos, non é un invento dos falanxistas indoctos e extremistas que no franquismo fan circular por Galicia un célebre panfleto que di: «HABLE BIEN. Sea patriota No sea bárbaro. Es de cumplido caballero que $V d$. hable nuestro idioma oficial, o sea, el castellano. Es ser patriota. VIVA ESPAÑA Y LA DISCIPLINA Y NUESTRO IDIOMA CERTANTIVO. ¡AARRIBA ESPAÑA!! Imprenta Sindical»

Como xa dixemos, estas ideas e mesmo citas de Amado Alonso, provenientes do seu mestre Pidal en gran medida, seguen hoxe no libro de Lapesa e en tódolos manuais que del derivan, fonte de estudio e información nas facultades de filoloxía do Estado español, mesmo nas galegas.

Na súa furia imperialista Amado Alonso dá toda unha enchente de citas a prol do imperialismo lingüístico castelán, xustificado sempre pola superioridade intrínseca do castelán sobre o resto de linguas de España: Mirad cómo desplegadas al aire las banderas españolas para correr en triunfo la Europa, se despliega también con ellas la hermosa habia Castellana, y ejecuta conquistas no menos memorables por gentileza y galanía en las Damas y Cortesanos, por interés propio en los Sabios y Literatos, por respeto y política en los Congresos y Gabinetes / Que ansí vimos que, al tiempo que su magestad [Carlos V] venció la batalla a Lansgrave y al duque de Sajonia junto al rio Albis, vinieron todas las señorías y principados de Alemania a se le sujetar y obedecer y a demandarle perdón. Y todos le hablaban en español, aunque parece algo por le complacer. Vemos que se na cita primeira se fala de galanura, beleza da lingua castelá sobre as outras ou mesmo de mellor capacidade para a literatura e a ciencia, na segunda cita non reapara Amado Alonso en que moitos adoptaban o 
español para facerlle gracia 6 poderoso emperador e ós seus exércitos: $Y$ todos le hablaban en español, aunque parece que era algo por le complacer.

\section{A DESCUALIFICACIÓN DA OPOSICIÓN}

Para Amado Alonso, como antes para Pidal, tódolos que non aceptan esta visión dos feitos, esta preponderancia de Castela, máis moderna, enérxica e vital e polo tanto cunha lingua superior, son simplemente uns envexosos, resentidos, frustrados e mesmo a antiEspaña. Métense no mesmo saco cós herexes, os non catolicos. Así retoma a vella crítica que Pidal facía 6 autor anónimo dunha Gramática de la lengua vulgar de España, que se publicou en Lovaina en 1559 e que, como vimos no capítulo dedicado a Pidal, xa merecera duras labazadas morais do mestre e fundador da Escola Lingüística Española. Amado Alonso remata a faena que iniciara o mestre. Cita que o anónimo autor da gramática dá como españolas non só o castelán senón tamén outras linguas da Península coma o éuscaro, o catalán e mesmo a linguaxe arábiga que aínda se conserva en zonas... Di que os que chaman español 6 castelán erraron pois vemos que en España hay más de una lengua, y otras más antiguas que no esta, y de más lustre... Isto alporiza a Amado Alonso. Non analiza cientificamente nin pausadamente o que di; non reflexiona que na data de 1943, cando Alonso escribe o libro que comentamos, seguen a existir galego, catalán e vasco e mesmo tiveron os seus rexurdimentos, foron recoñecidas como linguas cooficiais co castelán na República.... Di que o autor anónimo fala asi porque evidentemente no era castellano y, casi seguro era del reino de Aragón. Al enumerar los reinos peninsulares... ;con qué cuidado pone a las dos Castillas en el medio, alejándolas de las preeminencias inicial y final! Castilla es uno de los tantos reinos.... O autor na cita dos reinos só segue un criterio xeográfico de citalos de oeste a leste, pero iso non o soporta $\mathrm{D}$. Amado. $\mathrm{O}$ de ser aragonés non sabemos de onde o saca: sen dúbida vén do anticatalanismo de D. Amado. Pero non di Cataluña, porque Cataluña-catalán, Galicia-galego, Euskadiéuscaro, son palabras que hai que evitar na Escola Lingüística Española, como $x a$ sinalamos. Pero aínda segue don Amado: $Y$ de repente salta el celo regionalista de lo patrimonial, la buena opinión sobre la región propia y el voceo de sus excelencias, que implican, un poco provincianamente, el desmedro de los vecinos. Este hombre más razonador que razonable, que al rechazar el nombre de español... no se conforma con reclamar igualdad de derechos para todas las regiones..., sino que pospone a Castilla con visible inquina que le nubla el entendimiento...: este gramático que desecha el nombre de lengua española porque hay otras lenguas también españolas... Como se pode observar a Amado Alonso parécelle moi ben que os casteláns estean orgullosos da súa lingua, o cal é moi lóxico e normal, das súas tradicións, etc., pero non lle recoñece os mesmos dereitos 6 resto das comunidades de España. Castela ten que prevalecer e o bo español, na lingua, na ideoloxía, nos valores, 
É o que se adapta 6 castelán e ós valores que Amado Alonso di que representa. Despáchao dicindo que é falso e impertinente. Certamente non ofrece datos, estatísticas, teorías, etc., simplemente aldraxes e improperios.

\section{OS RESENTIDOS CONTINUADORES REXIONALISTAS DO ANÓNIMO GRAMÁTICO DE LOVAINA}

Os lingüistas, escritores, literatos, etc., que nos séculos XIX e XX van cultivar ou tentar normalizar as linguas non castelás son incluídos por Amado Alonso no caixón de Celos regionalistas anticastellenos. Son persoas resentidas que non aceptan la gigante personalidad de Castilla como región conformadora y directora de España, cuando en la vida real de los andaluces, aragoneses, catalanes, valencianos, gallegos, se tenia que contar a todas horas con la omnipresente vitalidad de Castilla... De novo Castela é a vitalidade, entendida como superioridade. Por outra banda, esta vitalidade non cambia de donos. A periferia por definición nunca pode ser máis vital co centro, de aceptar esta teoría nieztscheana e fascistoide da vitalidade. Amado Alonso conclúe que tanto o anónimo gramático de 1559 , como os que agora son presa dos celos rexionalistas, recomido de celos regionales, quedarían amansados por la nobleza castellana e polo triunfo da literatura e da lingua de Lope de Vega.

Pero don Amado non se corta. Di que o característico de Castela, tanto na lingua como na política, é o constructivo; as rexións, máis as bilingües, supoñen fragmentación, esmigallamento da patria; son de apartadiza idiosincrasia. Gracias que existe por parte de Castela un triunfante tesón de hegemonía. E don Amado para explicar a propagación do castelán inventa un concepto novo na linguística, que non define nin explica pois di que León y Aragón [evidentemente nunca Galicia, Cataluña, Euskadi, nomes nefandos e tabús na escola española] se irán castellanizando a su vez por infiltración progresiva.

Unhas liñas máis abaixo do seu ensaio parece desenvolver dun xeito práctico en que consiste a chamada infiltración. Di que, co castelán, non evidentemente co galego, -non existen para el os Cancioneiros, os documentos galegos, mesmo a predicación medieval en galego, non existe o Rexurdimento nin o movemento rexenerador das Irmandades, descoñece as polémicas do Congreso sobre o castelán e as linguas de España-nace el arte de la palabra, la literatura, y con ella la caída se convierte [desde o latín imperial] se convierte en ascensión... O castelán parte dos artistas de la palabra y de los guías sociales y culturales, y que, desde su creciente altura y dignidad social y artística, se impone como dechado e ideal a la masa y a las diversas regiones. Como vemos Amado Alonso, aproveita as ideas orteguianas de elite e masa para indicar que os galegos, cataláns, etc., son a masa e as súas linguas propias da masa. Os casteláns son a elite e a súa lingua é a propia das elites. Lembremos 
que Ortega foi un dos asinantes da proposta defendida por Unamuno nas Cortes constituíntes de 1931 que pedía para o castelán a primacía e que defendía para el o nome de español, oposto ás propostas defendidas por Castelao e os galeguistas nestas mesmas Cortes, como estudiaremos no citado libro.

Por outra banda, segue don Amado, é o castelán o idioma dos máis cultos, o lo que es lo mismo la aparición de un ideal de lengua realizado por los más capaces y que actúa sobre los demás como dechado... Por iso, engade unhas saborosas citas de gramáticos do XVII e XVIII para proba-lo dechado e perfección do castelán-español fronte ós idiomas rexionais ou o español regional: ... Montañeses y Gallegos usan de otra infinidad de vocablos con tan mal sonido que nos mueven a risa... / Los Gallegos, con mezcla de palabras y pronunciación portuguesa...

O castelán supón o despertar dunha cultura superior, que cómpre aceptar con complacido acatamiento, como lle corresponde ó criado co señor. Ademais, fronte os antes chamados apartadizos, Castela e a súa lingua traen un nuevo destino de aglutinador de la magna nacionalidade que se está formando. Todo o demais, linguas e culturas non castelás, son visiones de campanario.

Como remate para envexosos e resentidos nacionalistas toma unha cita de Correas, antítese do resentido gramático anónimo de Lovaina de 1559: Lengua se llama la habla de cualquiera nación. La nuestra se llama castellana, porque se habla y es propia de Castilla, nación principal de España, la mayor y más mediterránea, y della se extiende a las otras provincias, hasta a las que tienen diferente dialecto; y como más universal se llama también Española. E como non podía ser menos, toma tamén de Correas a cita en que o español é lingua de homes: ... la serpiente en el Paraíso Terrenal habló en Tudesco cuando engañó a Eva, y Eva en italiano, y Adán en español, denotando la habla española por varonil, habla de hombre varón; la italina, de mujer femenina; la tudesca, no humana, malsonante y dura. Aínda engade en nota outra cita dun gramático tamén do XVII, en que se relata a anécdota de que para falar con Deus o políglota Carlos V utilizaba o castelán: en el Paraíso terrenal se habian hablado lenguajes diferentes...: la serpiente habló en inglés...; la mujer en italiano, por zalamera; el hombre en francés, por varonial; pero Dios en castellano, por ser lengua graciosa y divina... Carlos $V$, que para hablar a su caballo siempre hablaba la lengua alemana; para hablar a una mujer la italiana; para hablar a un hombre, la francesa; mas para hablar a Dios, la Catellana... Evidentemente, don Amado non cre que no paraíso Deus falase en castelán, pero realiza estas citas cunha compracencia de caerlle a baba: como non vai ser superior o castelán se ata os antigos a facían lingua de homes, lingua do paraíso... Só os resentidos para el rexionalistas -nunca nacionalistas-, tataranetos do resentido anónimo aragónes - ¿ou catalán?gramático de Lovaina de 1559 poden dicir o contrario.

Seguindo coa súa teima acepta, acriticamente, que o castelán é falado no XVIII en toda España. Así xa di Mayáns e Siscar que o español é a lingua que se usa maioritariamente en tódalas rexións de España, mesmo nas bilingiies. 
Vese que don Amado nunca viaxou a Galicia, pois decataríase do contrario, ou que nunca deu unha volta por Cataluña. Tampouco debía ler os xornais da República, onde Castelao afirmaba o contrario no Parlamento, ou os deputados catalanistas e vascos. Por outra banda, é aceptado sen máis o castelán como superior instrumento de comunicación intrarregional. A escola española, tan científica noutros temas, acepta sen máis os argumentos de autoridade de calquera cando se refiren ó uso do castelán nas rexións non castelás. Na súa Historia de la lengua española, e na edición de 1981 Lapesa acepta que o castelán era xa lingua propia de Galicia e que desprazara ó galego no século XVI, porque así o afirma Juan de Valdes no seu Diálogo de la lengua.

Por outra banda, os que non aceptan o nome de español, os que cren que esta preminencia non é xusta pola superioridade literaria, cultural, etc., do castelán, non só son resentidos e malos patriotas son tamén aldéans e pailáns: En las ciudades españolas es más frecuente llamar a nuestro idioma español; en los campos, castellano. Español vive más entre la gente ilustrada... Xa vimos cómo a tradición dos gramáticos e intelectuais galegos non é esa. O que lea o Sempre en Galiza de Castelao, a xeración Nós, os lexicógrafos e gramáticos galegos, os intelectuais que escriben sobre o idioma, etc., e xa desde Pintos, como sinalamos no capítulo anterior, falan de castelán. Mesmo Castelao e a xeneralidade de intelectuais galegos, como veremos e como estudiou recentemente o profesor Monteagudo Romero en Castelao: Defensa e ilustración do galego, contrapoñen castelán-español e consideran español como expresión do expansionismo castelanista dos seguidores de Menéndez Pidal, Unamuno ou Ortega, en definitiva xa non só da Escola Lingüî́stica Española, senón da intelectualidade españolista, serán para Amado Alonso, e para a Escola Española aldeáns, pailáns, xente resentida, apegados ó espírito de campanario, opostos 6 universalismo... Pobres Pintos, Saco e Arce, Murguía, Castelao...

A inquina de Amado Alonso contra os que el considera os resentidos continuadores do envexoso gramático anónimo de 1559 chega á crueldade, pois estes que non aceptan español por castelán, os que non aceptan a superioridade da lingua castelâ, que se impón ás demais por infiltración, en definitiva porque é mellor en tódolos sentidos e símbolo da verdadeira patria, sen particularismos separatistas non saben que Hay unos hombres que hacen la historia y otros a quienes se la hacen. Conclúe que os bilingües de hoxe, 6 denominaren castelán o que para el é español, se resisten al nombre de español para el idioma nacional obedecen a las mismas tendencias... que los regionales del XVI que se resistian al castellano...

\section{A OPOSICIÓN DE CASTELAO}

Estas ideas de Pidal e a súa escola, asumidas pola intelectualidade castelá da época, como Unamuno ou Ortega, tiveron ampla difusión nos debates das 
cortes constituíntes da II República, cando se discutían os artigos da Constitución republicana referentes á consideración que debían ter nesta as linguas de España.

Castelao, voceiro das teorías lingüísticas tradicionais galegas das Irmandades, Risco, Villar Ponte, etc., defende no Parlamento de Madrid o 18 de setembro de 1931 unha emenda, moi moderada, pero que tentaba mellorar a situación do galego na constitución republicana, así como tamén as das outras linguas non castelás. A emenda asinada por Castelao, Otero Pedrayo, Suárez Picallo, Poza Juncal, Ramón María Tenreiro, A. Villar Ponte, Alejandro Rodríguez Cadarso, Gómez Paratcha e Osorio Tafall indicaba que El castellano es el idioma oficial del Estado. Ni legislativa ni administrativamente se coartará el uso de la lengua propia en las diferentes regiones. Por outra banda, o catalán xa estaba recoñecido como lingua cooficial en Cataluña xunto co castelán por unha serie de decretos emitidos pola República. Castelao no seu discurso para defender a emenda sinala esta situación de recoñecemento do catalán; sinala que o galego desde a época dos Reis Católicos figura prohibido na Administración, nos tribunais, no ensino e na igrexa. Sinala que así xorde a diglosia castelángalego e ata o autoodio dos galegos: los niños de las escuelas gallegas crean que hablar el castellano es hablar bien, y que hablar gallego es hablar mal. Castelao engade que o galego é a lingua propia de Galicia, especialmente dos sectores populares, maioritarios na poboación: es la lengua del trabajador, del obrero, del artesano, del labriego, del marinero. Fronte a este presente precario do galego lembra que na Idade Media foi lingua de vasallos y magnates, y solo despreciada por esos señoritos cursis y desocupados de las capitales de provincia. Lembra o rexurdimento, o seu carácter progresista e o carácter civil da literatura galega, pois un dos tópicos esgrimidos polos opositores á normalización do galego, mesmo dos actuais, é a identificación do galego e a súa reivindicación con atraso e mesmo co carlismo, que mira, segundo eles, cara ó pasado e que desexa volver á Idade Media. Fronte 6 españolismo excluínte de Pidal e os seus seguidores -0 español é a lingua española por antonomasía e a única que merece este adxectivo, como xa vimos-Castelao sinala que tan españolas coma o castelán son o catalán e o vasco, nunha nova concepción do español como conxunto de diferencias enriquecedoras e oposto 6 uniformismo castelanista exluidor. A continuación relata a célebre anécdota de que os animais aínda están na linguaxe universal común, que aparecerá reelaborada en Sempre en Galiza, e hoxe é texto canónico reproducido en tódolos libros de texto, malia as burlas, expresivas da maior ignorancia, que lle suscitan 6 académico da Española e catedrático de Filoloxía Gregorio Salvador no seu libro Español e lingua de Españas, como analizamos polo miúdo no próximo libro. Fixémonos que a emenda e o discurso son moi moderados, non hai nin unha sospeita de separatismo: Castelao acepta que o castelán, chamado castelán e non español, é a lingua do Estado, que é tamén oficial nas comunidades bilingües e s 6 pide a cooficialidade das linguas non castelás nas comunidades bilingües. Por outra banda, estas linguas son para castelán tan españolas coma o propio castelán. Sen embargo, isto non é suficiente para os defensores do españolismo a ultranza e da idea de que o castelán, para 
eles español, é a única lingua de España. Neste sentido a resposta nesta mesma sesión das Cortes de Miguel de Unamuno é antolóxica.

Miguel de Unamuno, na mellor liña do españolismo pidaliano, defende unha emenda, asinada por intelectuais casteláns tan caracterizados como Ortega y Gasset, Alfonso García Valdecasas, Díaz del Moral ou B. Giner de los Ríos, que di: El español es el idioma oficial de la República. Todo español tiene el deber de saberlo y el derecho de hablarlo. En cada región se podrá declarar oficial la lengua de la mayoría de sus habitantes. A nadie se le podrá imponer, sin embargo, el uso de ninguna lengua regional. X. Antonio Durán sinalou xa alá polos anos setenta no seu fermoso artigo «La lengua gallega a debate (recuerdo a propósito de la discusión actual, de la disputa en las Constituyentes de la II República. El discurso de Castelao)» o españolismo exclusivista de Unamuno, pero non só de Unamuno senón do restos dos caracterizados intelectuais españois que asinan a emenda, entre os que destaca o todopoderoso daquela Ortega y Gasset. Recentemente volveu sobre o tema Henrique Monteagudo en «Castelado versus Unamuno. $O$ debate sobre a oficialidade dos idiomas nas cortes constituíntes da II República», que segue de cerca o citado artigo Durán. Subliñemos cómo Unamuno cambia castelán por español. Por outra banda a lengua propia das diferentes rexións, da emenda de Castelao, pasa a ser a lingua regional -oposto a español-, coma se estas linguas xa non fosen españolas. Ademais, desaparece o sintgma lingua propia, pois xá sabemos, como vimos antes, que Pidal, Amado Alonso e a espola española consideran que o castelán é lingua tan propia e característica das comunidades bilingües coma a lingua de seu destas: catalán, galego e éuscaro. No discurso parlamentario de Unamuno que estamo a comentar, D. Miguel chega a dicir que a verdadeira e auténtica Rosalía era a que escribía en castelán, non a que o facía en galego. Ademais, como ben intúe Monteagudo, moi perigosa é a afirmación da emenda dos intelectuais castelanistas de que en cada región se podrá declarar oficial la lengua de la mayoría de sus habitantes. ¿Pero claro, cal é a lingua da maioría dos habitantes dunha comunidade bilingüe, o castelán ou a lingua propia? No seu discurso parlamentario Unamuno engade que en Navarra $x a$ non é lingua da maioría dos navarros o éuscaro, nin sequera na propia Euskadi. Cando se refire ó galego, Unamuno di que o seu caso é similar ó do vasco e que tampouco cre que sexa a lingua da maioría dos galegos, como ocorre en Euskadi: Pasemos, como digo a Galicia. Tampoco allí hai problema. No creo que en una verdadera investigación resultara semejante mayoría. No me convencen de eso.» Como se ve, Unamuno, fronte á afirmación do discurso de Castelao de que Galicia fala galego maioritariamente e case absolutamente, pois o pobo é galegofalante e só os señoritos cursis da capital de provincia usan - castelán, di que o castelán é xa a lingua majoritaria de Galicia. Xa que logo, o castelán será, chamado xa español, a lingua oficial de Galicia; o galego, de ningún xeito, posto que xa non é lingua maioritaria. Por outra banda, aínda engade D. Miguel que a cooficialización das linguas non castelás supón un ataque a sagrada unidade de España, alicerzada nun único idioma común: o castelán, para el e os seus español. 
Unamuno tamén minusvalora a literatura galega neste discurso pois afirma que un literatura de ton quejumbroso, e exemplifícaco jcon Curros! Non sabe don Miguel, como ben sinala Alonso Montero, que non hai literatura máis cívica cá literatura galega.

A XEITO DE CONCLUSIÓN

Xa que logo a escola lingüística española e mesmo a intelectualidade castelá máis caracterizada -0 propio Ortega- elaboran un discurso sobre o galego -tamén sobre as outras linguas de España non castelás- que para nada ten en conta a realidade sociolingüistica nin cultural destas comunidades. $O$ discurso, como tentaremos demostrar polo miúdo nun libro de próxima aparición, continúa hoxe en dia. 